\title{
Phonological spelling errors in the writing of Greek dyslexic children: in support of the phonological deficit theory
} Angeliki Zachou* and Ioannis Zachos

\author{
Address: Center for Psychological Research, Athens, Greece
}

* Corresponding author

from International Society on Brain and Behaviour: 3rd International Congress on Brain and Behaviour

Thessaloniki, Greece. 28 November - 2 December 2007

Published: 17 April 2008

Annals of General Psychiatry 2008, 7(SuppI I):SI 43 doi:I0.I I86/I744-859X-7-SI-SI 43

This abstract is available from: http://www.annals-general-psychiatry.com/content/7/SI/SI 43

(c) 2008 Zachou and Zachos; licensee BioMed Central Ltd.

\section{Background}

Developmental dyslexia is defined as the specific difficulty in the acquisition of reading and writing, within normal I.Q. range. One of the most dominant theories for the origins of developmental dyslexia is the one of the "phonological deficit hypothesis". The aforementioned theory supports that a cognitive deficit affects the representation and processing of speech sounds.

\section{Materials and methods}

In the present research we examine the manifestation of this deficit within the framework of Modern Greek. 451 officially diagnosed (and at risk) dyslexic children's writing samples of all levels of the primary school were analyzed and compared to 1.612 children's writing samples of general school population.

The experimental material that was implemented is a subtest of the "Test Battery for the Assessment of Dyslexia in Greek (Zachos D. \& Zachos I, 1998). More particularly, it was the Dictation-Spelling Task, which consists of six different texts, adapted to each one of the six levels-classes of primary school and examines several factors of spelling abilities. However, for the present research we shall present the results of the Phonological category.

The performance of each student is controlled by means of correct spelling.

\section{Results}

The results were analyzed quantitatively and can be summarized as follows:
- ll the groups of dyslexic children achieved significantly low scores compared to the control groups

- Dyslexic children's results were more deviant, contrary to the control groups, where the results were more homogeneous

- As the level increased dyslexic children's performance was better but still significantly lower

\section{Conclusions}

The low performance of dyslexic children reveals the manifestation of phonological deficit in Greek and is compatible to the Phonological Deficit Theory of Developmental Dyslexia. The fact that these errors persist in the course of time implies the need for a more accurate diagnosis as well as for an effective treatment.

\section{References}

I. Snowling M. J: Dyslexia, Blackwell Publishers; 2000.

2. Vellutino F. R., Fletcher J. M., Snowling M. J., Scanlon D.M.: Specific Reading disability (dyslexia): what have we learned in the past four decades? Journal of Child Psychology and Psychiatry 2004, 45(I):2-40.

3. Zachos D., Zachos I.: Diagnostic Test Battery for Dyslexia in Greek. Center for Psychological Research 1998.

4. Zachos I., Zachou A., Tomaras N., Kosmopoulos I., Zachos D.: Performance of primary school children. 2007. Ist Panhellenic Conference on Special Education, Department of Primary EducationUniversity of Athens, Greek Society for Special Education 